ESTUDOS RB:P

\title{
Expansão do ensino médio no Estado de Mato Grosso do Sul no período de 1999 a 2009
}

Dirce Nei Teixeira de Freitas

\section{Resumo}

Resultando de pesquisa quanti-qualitativa com enfoque descritivoanalítico e crítico, o texto trata da expansão e dos desafios do ensino médio estadual sul-mato-grossense na última década, bem como das medidas governamentais promotoras da qualidade desse ensino. Revela que o Estado optou por expandir o atendimento pela adoção da modalidade educação de jovens e adultos (EJA), tendo criado mecanismos de estímulo à migração das matrículas do ensino médio noturno para essa opção e arranjos de diversificação e flexibilização, além de alterações curriculares. A análise desse quadro aponta desafios e sugere via alternativa para a qualificação do ensino médio estadual.

Palavras-chave: ensino médio; expansão do ensino; política educacional. 


\section{Abstract}

Expansion of upper secondary education in Mato Grosso do Sul State in the 1999-2009 period

This article presents the results of a quantitative and qualitative research with a critical descriptive and analytical focus. The work addresses the expansion and the challenges faced by the state high school system of Mato Grosso do Sul in the last decade, as well as the government policies aiming at improving the quality of upper secondary education. It reveals that the state has chosen to expand the offer of this modality by means of the Education of Yong People and Adults (EJA) program, creating mechanisms to stimulate a migration from high school night course enrollments to EJA program, introducing new diverse and flexible arrangements, and making curricular changes. The analysis of this scenario points out challenges and suggests an alternative route for improving the quality of upper secondary education in the state.

Keywords: upper secondary education; expanding education; educational policies.

A educação básica é reconhecidamente indispensável ao desenvolvimento individual e social. No Brasil, desde 1996, passou a ser o primeiro nível da educação escolar, sucedido pela educação superior. É composta por três etapas regulares interligadas - educação infantil (0 a 5 anos), ensino fundamental (6 a 14 anos) e ensino médio (15 a 17 anos) - e, também, por modalidades de atendimento (educação de jovens e adultos, educação especial, educação escolar indígena).

Até a Emenda Constitucional n 59/2009, o ensino obrigatório no Brasil era o fundamental. Porém, a legislação determinou a gradativa universalização do ensino médio ante o generalizado reconhecimento da insuficiência do ensino fundamental para maior aprimoramento individual e melhor formação do cidadão e do trabalhador, bem como para o desenvolvimento do País. Assim, a segunda e a terceira etapas da educação básica tornaram-se o foco das políticas públicas concebidas e implementadas no complexo contexto federativo do País, em anos recentes.

Para a efetivação dessas duas etapas, proliferaram formas de oferta de ensino (classes hospitalares, unidades prisionais, a distância e outras), adotou-se um enfoque da educação especial na perspectiva da inclusão escolar e estimularam-se a diversificação, a diferenciação e a flexibilização do atendimento (especialmente na educação de jovens e adultos, na educação escolar indígena, na educação do campo, entre outras).

Na primeira etapa, educação infantil, a expansão da oferta se deu principalmente no pré-escolar (4 e 5 anos), embora tenha aumentado o 
atendimento em creche, que passou a compor a educação escolar, deixando de ser mera assistência social.

Com a universalização do acesso ao ensino fundamental pela população de 7 a 14 anos e os avanços obtidos na regularização do fluxo escolar, cresceu a demanda pelo ensino médio (Oliveira, 2007), em face da qual foram organizadas iniciativas nacionais e estaduais diversas.

Nesse cenário geral brevemente descrito, podem ser vistas distintas realidades, devido, principalmente, às muitas desigualdades existentes no País. Interessa-nos, neste trabalho, analisar especificamente o quadro configurado no Estado de Mato Grosso do Sul (MS), na primeira década do século 21, no que diz respeito à expansão do ensino médio e aos desafios decorrentes.

Com esse propósito, iniciamos delineando os contornos mais gerais da educação básica no Estado para, a seguir, analisarmos a expansão do ensino médio, uma vez que a efetividade social dessa etapa tem sido historicamente problematizada.

Mesmo sem adotar uma metodologia elaborada de análise dos dados quantitativos, a abordagem aqui realizada coloca em evidência aspectos importantes da política de expansão e qualificação do ensino médio, que são de especial interesse para sul-mato-grossenses e brasileiros que vivem situação similar, até porque ainda são escassas as pesquisas que tratam dessa questão nesse espaço subnacional.

Utilizamos dados e indicadores estatísticos disponíveis nas bases on-line do Instituto Nacional de Estudos e Pesquisas Educacionais Anísio Teixeira (Inep), informações obtidas com a Secretaria de Estado de Educação de Mato Grosso do Sul (SED/MS), legislação e documentos informativos oficiais nacionais e estaduais.

Usamos também dados quanti-qualitativos levantados em 10 escolas estaduais de ensino médio do Estado de MS (Freitas, 2003) no contexto da pesquisa Ensino médio noturno: registro e análise de experiências (Oliveira, Sousa, 2008), financiada pela Organização das Nações Unidas para a Educação, a Ciência e a Cultura (Unesco) e pelo Ministério da Educação (MEC) e realizada no ano de 2003 por pesquisadores de oito Estados brasileiros numa amostra de 80 escolas. Utilizando essas fontes, pretendemos evidenciar peculiaridades da expansão do ensino médio sul-mato-grossense na primeira década deste milênio, destacando desafios para a política educacional e providências necessárias.

O texto está organizado de modo a oferecer uma visão da expansão da educação básica e do ensino médio no MS, bem como das iniciativas governamentais no período de 1999 a 2009, destacando desafios e indicando vias que parecem necessárias para avanços qualitativos.

\section{A expansão da educação básica escolar no Estado}

A simples observação da variação da matrícula inicial na educação básica sul-mato-grossense, no período de 2000 a 2009 (Tabela 1), 
permite-nos constatar aspectos importantes da política de expansão do ensino médio concretizada no Estado.

Tabela 1 - Matrícula inicial na educação básica e sua variação Mato Grosso do Sul - 2000/09

\begin{tabular}{|c|c|c|c|c|c|}
\hline $\begin{array}{l}\text { Etapas e } \\
\text { modalidade } \\
\text { EJA }\end{array}$ & $\begin{array}{l}2000 \\
\text { Número de } \\
\text { matrículas }\end{array}$ & $\%$ & $\begin{array}{l}2009 \\
\text { Número de } \\
\text { matrículas }\end{array}$ & $\%$ & $\begin{array}{c}\text { Variação } \\
2000 / 09 \\
\%\end{array}$ \\
\hline $\begin{array}{l}\text { Educação } \\
\text { infantil }\end{array}$ & 59.911 & 9,1 & 84.486 & 12,6 & 41,0 \\
\hline $\begin{array}{l}\text { Ensino } \\
\text { fundamental }\end{array}$ & 459.475 & 70,1 & 413.335 & 62,0 & $-10,0$ \\
\hline Ensino médio & 88.795 & 13,5 & 91.342 & 13,7 & 2,9 \\
\hline $\begin{array}{l}\text { Educação } \\
\text { de jovens e } \\
\text { adultos (EJA) }\end{array}$ & 47.893 & 7,3 & 78.325 & 11,7 & 63,5 \\
\hline Total & 656.074 & 100,0 & 667.488 & 100,0 & 1,7 \\
\hline
\end{tabular}

Fonte: Inep/MEC (Edudata e Educacenso).

Os dados mostram que a maior variação nas matrículas iniciais no período de 2000 a 2009 ocorreu na modalidade educação de jovens e adultos (EJA), chegando a 63,5\%, e a seguir na educação infantil, que alcançou variação positiva da ordem de $41 \%$. No ensino fundamental, a variação das matrículas foi negativa $(-10 \%)$ e no ensino médio positiva, mas pequena (2,9\%). No total geral, a variação das matrículas foi positiva no período, porém ficou apenas em 1,7\%.

Portanto, podemos afirmar que a expansão das matrículas na educação básica não se deu, no MS, pela via das etapas de ensino regular, mas pelo crescimento do atendimento no ensino fundamental e no médio na modalidade EJA. Basicamente, a política de regularização do fluxo escolar no ensino regular impactou a demanda pela EJA, sendo esta estimulada por meio de medidas do governo estadual mencionadas na terceira seção deste texto.

Analisadas no conjunto, as matrículas na educação básica ao término da primeira década dos anos 2000 indicam uma lenta redução da desproporção no atendimento das suas etapas regulares (educação infantil, ensino fundamental e ensino médio), sendo essa diminuição ainda mais morosa no ensino médio. Em 2000, a proporção das matrículas iniciais no ensino médio em relação ao total de matrículas da educação básica era de 13,5\%, mantendo-se, em 2009, muito próxima disso: 13,7\%.

Considerando que no Estado de Mato Grosso do Sul o atendimento ao ensino médio (regular e não regular) é historicamente tarefa da dependência administrativa estadual complementada pela dependência privada, é importante observar especificamente as matrículas estaduais (Tabela 2). 


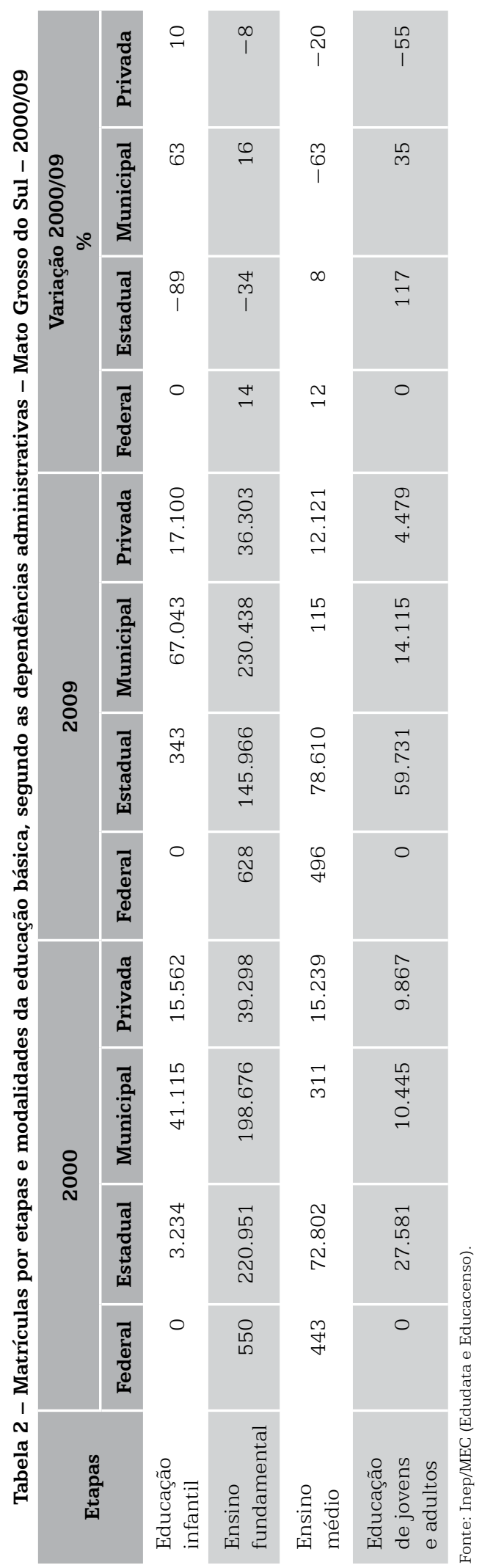


A variação das matrículas na educação infantil no período de 2000 a 2009 foi expressiva na esfera municipal (63\%) e positiva, embora pequena, na esfera privada (10\%), sendo acentuadamente negativa na estadual (-89\%).

O esforço municipal fica evidente quando observamos a dimensão da variação das matrículas na educação infantil sob a vigência do Fundo de Manutenção e Desenvolvimento do Ensino Fundamental e de Valorização do Magistério (Fundef) em comparação com o período em que passa a vigorar o Fundo de Manutenção e Desenvolvimento da Educação Básica e de Valorização dos Profissionais da Educação (Fundeb), cuja proposta de gestão do financiamento abarca todas as etapas da educação básica e o fundo anterior.

As matrículas municipais em creche e pré-escola, que em 2003 eram 40.711, passaram a 61.186 em 2006, ou seja, tiveram um aumento superior a 50\% nos três anos que antecederam a implantação do Fundeb. Três anos após a introdução desse novo fundo, em 2009, as matrículas municipais chegaram a 67.043, registrando, portanto, uma variação de apenas 9,6\% em relação a 2006, quando o esperado era um aumento maior.

A variação das matrículas no ensino fundamental, no período de 2000 a 2009, foi positiva nas dependências administrativas municipal e federal, mas negativa na estadual e na privada. Em valor absoluto, o atendimento municipal é o maior do conjunto das dependências administrativas consideradas.

A expressiva variação negativa das matrículas estaduais na educação infantil e no ensino fundamental não coincide com uma variação positiva importante nas matrículas no ensino médio regular, mas, sim, nas matrículas na modalidade EJA.

Em face disso, decidimos observar especificamente as matrículas estaduais nessa modalidade (Tabela 3).

Tabela 3 - Matrícula inicial estadual na modalidade educação de jovens e adultos (EJA) - Mato Grosso do Sul - 2000/09

\begin{tabular}{|l|c|c|c|c|c|}
\hline \multicolumn{1}{|c|}{ EJA } & \multicolumn{2}{|c|}{2000} & \multicolumn{2}{c|}{2009} & $\begin{array}{c}\text { Variação } \\
\text { 2000/09 } \\
\%\end{array}$ \\
& Número & $\%$ & Número $^{(1)}$ & $\%$ & \\
\hline $\begin{array}{l}\text { Ensino } \\
\text { fundamental }\end{array}$ & 22.121 & 81 & 32.159 & 54 & 45 \\
\hline Ensino médio & 5.276 & 19 & 27.572 & 46 & 422 \\
\hline Total & $\mathbf{2 7 . 3 9 7}$ & $\mathbf{1 0 0}$ & $\mathbf{5 9 . 7 3 1}$ & $\mathbf{1 0 0}$ & $\mathbf{1 1 8}$ \\
\hline
\end{tabular}

Fonte: Inep/MEC (Edudata e Educacenso).

Nota: ${ }^{(1)}$ Inclui os alunos da EJA integrada à educação profissional.

A variação total das matrículas na EJA em 2009 foi de 118\% em relação a 2000. No ensino fundamental, a variação das matrículas foi de $45 \%$, e no ensino médio chegou a $422 \%$.

Constatamos que a modalidade EJA foi a via adotada, pela dependência administrativa estadual, para que o dever estatal da oferta de atendimento 
aos não escolarizados em idade própria fosse efetivado com eficiência, ou seja, por meio de uma estratégia que combina administração da escassez de recursos e economia de esforços e tempo.

Se a eficiência é um requisito necessário à atuação pública responsável e democrática (Cury, 2002), também pode não ir além de estratégia de priorização da contenção dos custos adicionais que implicam as taxas brutas de matrícula, a que se referiu Schwartzman (2005) ao tratar dos desafios da educação no Brasil. Assim, em virtude das disposições constitucionais republicanas e democráticas e do desafio de escolhas profícuas para o futuro, cabe avaliar a lógica que impulsiona a expansão da educação básica estadual.

Nessa avaliação, vale examinar que qualidade em matéria de educação escolar tem sido propiciada àqueles que não tiveram o seu direito à educação efetivamente protegido no momento adequado. E que materialidade ela permite à proteção educacional ao adolescente, uma vez que este e a criança têm seu atendimento integral priorizado no nosso ordenamento legal.

Reconhecemos que tal avaliação é de difícil realização, uma vez que o cenário diz respeito a iniciativas dos vários governos municipais (ao todo 78 no Estado), bem como dos governos estadual e federal. Envolve tanto o exercício das autonomias como o do regime mais ou menos colaborativo ou competitivo que se estabelece para além da área da educação.

Dados do Inep informam que tem crescido o número de concluintes da EJA. Em 2000, eles eram 9.318 e, em 2009, chegaram a 17.939, registrando um crescimento de 92,5\%. Entretanto, é preciso saber com que qualidade isso se dá.

Os impactos da expansão da EJA na sociedade e na vida dos indivíduos são diversos. Optamos por alertar para aqueles que incidem sobre a qualidade da escolarização regular básica e superior, uma vez que o reingresso na via regular não só é legítimo como também praticado. Sendo assim, é preciso que a avaliação educacional no Estado não se restrinja a aferir a qualidade do ensino fundamental, do ensino médio e da educação superior nas formas regulares de oferta, como se a qualidade resultasse apenas do que, como e quanto se realiza ou não na via regular de escolarização.

Não temos dúvidas de que o modo de expansão da educação básica mostrado pelos dados é uma escolha do poder público (Estado, governos, administrações, forças sociais hegemônicas) vista como a possível, dadas as condições objetivas existentes e uma cultura política conservadora no enfrentamento dos desafios sociais ligados à legítima e essencial satisfação de necessidades básicas da população.

Porém, é preciso considerar que essa escolha significa, como tem sido concretizado no Estado, o compromisso público com a qualidade da educação, questão que se tornou o mote das políticas públicas educacionais da primeira década dos anos 2000, em todos os âmbitos federativos. 


\section{A expansão do ensino médio estadual}

No ano 2000, a escolarização líquida no ensino médio sul-matogrossense, segundo dados do Inep, era da ordem de 34\% e a escolarização bruta chegava a 67,8\%. Esse quadro, mesmo desfavorável, exibia importante melhoria em relação ao ano de 1991, quando as taxas eram, respectivamente, de $18 \%$ e $43 \%$. O ensino médio (regular) chegara a mais pessoas na faixa etária própria e também fora dela.

A variação das matrículas no ensino médio no MS foi positiva no período de 2000 a 2003, chegando a 15,1\%. No entanto, seguiu negativa no período de 2004 a 2006, quando foi de $-2,4 \%$, e no intervalo de 2007 a 2008 , em que chegou a $-3,7 \%$.

O MEC constatou que, em 12 unidades da Federação, ocorreu queda nas matrículas no ensino médio, contrariando as expectativas de continuidade da expansão (Brasil, 2009). Isso, segundo o MEC, deve-se ao crescimento nos índices de reprovação, abandono, repetência e evasão no ensino fundamental, que reduz o número de concluintes aptos a cursar o ensino médio. Ainda que esse fator seja importante na explicação do ocorrido, para o caso do Estado de MS não nos parece que seja o mais decisivo, sendo esclarecedora a observação do quadro aí configurado na primeira década dos anos 2000 no ensino médio, tanto regular como na modalidade EJA (Tabela 4).

Tabela 4 - Matrículas iniciais no ensino médio regular e na modalidade educação de jovens e adultos (EJA) - Mato Grosso do Sul - 1999/2009

\begin{tabular}{|c|c|c|c|c|c|c|c|}
\multicolumn{9}{c|}{ Ensino médio regular } \\
\hline
\end{tabular}

Fonte: Inep/MEC (Edudata e Educacenso).

Observamos que a variação das matrículas iniciais no ensino médio regular foi positiva no período de 2002 a 2004 e em 2009, embora a 
recuperação do crescimento tenha sido mínima. A maior variação no período de 1999 a 2009 foi a registrada em 2002.

Quando observamos a composição etária das matrículas no ensino médio regular, verificamos taxas decrescentes de alunos com mais de 17 anos e, por outro lado, taxas crescentes de alunos com menos de 15 anos. Em 2000, do total das matrículas, 50,1\% correspondiam à faixa etária regular (15 a 17 anos), tendo esse indicador subido para 60,8\% em 2006.

É notável que a taxa de variação das matrículas no ensino médio na modalidade EJA tenha aumentado na maior parte do período de 1999 a 2009, sendo que a maior variação ocorreu em 2004. Isso reflete, em parte, o decréscimo das matrículas no ensino médio regular após esse ano. E a variação negativa nas matrículas da EJA observada em 2002 (-55,7\%) coincide com a maior variação positiva em relação a $2000(12,4 \%)$ nas matrículas no ensino médio regular.

Para melhor entendimento do ocorrido, decidimos observar esse quadro com o auxílio de dados relativos ao turno das matrículas (Tabela 5).

Tabela 5 - Matrículas iniciais no ensino médio regular diurno e noturno na dependência administrativa estadual - Mato Grosso do Sul - 2000/06

\begin{tabular}{|l|r|r|r|r|c|}
\hline \multirow{2}{*}{ Turnos } & \multicolumn{2}{|c|}{2000} & \multicolumn{2}{c|}{2006} & $\begin{array}{c}\text { Variação } \\
\text { 2000/06 } \\
\text { \% }\end{array}$ \\
\cline { 2 - 7 } & Número & \% & Número & \% & 71 \\
\hline Diurno & 26.312 & 46 & 45.037 & 53 & -14 \\
\hline Noturno & 46.490 & 64 & 40.102 & 47 & $\mathbf{1 7}$ \\
\hline Total & $\mathbf{7 2 . 8 0 2}$ & $\mathbf{1 0 0}$ & $\mathbf{8 5 . 1 3 9}$ & $\mathbf{1 0 0}$ & $\mathbf{1 0 0}$ \\
\hline
\end{tabular}

Fonte: Inep/MEC (Edudata e Educacenso).

A variação positiva das matrículas de alunos com menos de 15 anos observada (Tabela 4) está associada ao aumento do ensino médio diurno, que se apresentou 71\% maior no ano de 2006 em relação a 2000. Por outro lado, a variação positiva das matrículas na modalidade EJA (Tabela 4) explica a redução das matrículas no ensino médio regular de alunos com mais de 17 anos e a variação negativa de matrículas no ensino regular noturno no ano de 2006, comparativamente a 2000.

O significado desse quadro pode ser mais bem compreendido se não nos limitarmos a pensar nos ganhos da expansão do acesso assegurado pela EJA, mas atentarmos para a qualidade que ela traz. Não há dúvida de que é melhor ter do que não ter acesso à educação escolar, e nisso existe ganho qualitativo. A migração de adolescentes do ensino regular noturno para a EJA significa que se está a assegurar-lhes uma qualidade mínima, conforme mostra a próxima seção. Todavia, vivemos tempos em que tal qualidade não basta, tanto na perspectiva imediata como na mediata. Não cabe aqui discutir a EJA e sua qualidade, mas claro está que não é a via de escolarização mais fecunda nem a única possível num país bem posicionado no ranking da economia mundial. É certo que a 
escolha dessa via estreita horizontes de desenvolvimento individual e social, condenando também gerações futuras.

Cabe mencionar que a pesquisa sobre o ensino médio noturno no Estado de MS evidenciou duas tendências no período de 1997 a 2003: a de expansão do atendimento ao ensino médio regular a cargo da dependência administrativa estadual e a de expansão do ensino médio diurno. E sugeriu que as implicações dessas tendências fossem aquilatadas na formulação de políticas públicas.

Ajudam-nos também, na observação e na compreensão das peculiaridades do ensino médio regular no MS, as informações sintetizadas no Índice de Desenvolvimento da Educação Básica (Ideb). Calculado com base no Sistema Nacional de Avaliação da Educação Básica (Saeb) e no Censo Escolar, o índice observado no ensino médio regular estadual foi de apenas 2,8 no ano de 2005, sendo projetada a meta de 2,9 para o ano de 2007. Essa meta foi ultrapassada, uma vez que se chegou a 3,4 .

Esse resultado aparenta ser positivo, sugerindo, nos limites da concepção do Ideb, a melhoria da qualidade do ensino médio regular estadual sul-mato-grossense. Todavia, é preciso atentar para a metodologia adotada para alcançar aquele índice.

Para isso, são esclarecedores os dados concernentes ao acentuado e sucessivo crescimento das matrículas no ensino médio EJA após 2002 (Tabela 4), assim como a variação negativa das matrículas observada no ensino médio regular noturno juntamente com a variação positiva observada no ensino médio diurno (Tabela 5). Esses dados informam um movimento de migração de matrículas do ensino regular para a EJA, cujo reflexo beneficiou o Ideb exibido no ensino médio regular pela rede estadual sul-mato-grossense. Isso porque o índice foi aliviado do peso negativo da presença de parte da população com mais de 17 anos e do aluno trabalhador (noturno), cujo rendimento é sabidamente baixo. Assim, a estratégia de expansão adotada na política pública estadual teria operado como fator decisivo para a elevação do Ideb. Não é possível ignorar os estímulos governamentais ao redirecionamento da demanda no sentido da referida migração, do que falaremos mais adiante.

Os dados de desempenho cognitivo dos alunos da $3^{\mathrm{a}}$ série do ensino médio regular estadual mostram médias de proficiência em Matemática e Língua Portuguesa, respectivamente, de 11,5 e 12,7, mais altas no ano de 2005, comparativamente a 2003. Essa elevação ocorreu após o acentuado crescimento das matrículas na modalidade EJA em 2004 e a queda na taxa de abandono (Tabela 6) no ensino médio regular no ano de 2005, em relação a 2003. Por outro lado, é possível que o aumento da taxa de reprovação se deva a práticas avaliativas mais rigorosas por parte dos professores diante da modificação do perfil dos alunos do ensino médio regular. 
Tabela 6 - Taxas de aprovação, reprovação e abandono no ensino médio regular na dependência administrativa estadual Mato Grosso do Sul - 2001/05

\begin{tabular}{|c|c|c|c|}
\hline Ano & Taxa de aprovação & Taxa de reprovação & Taxa de abandono \\
\hline 2001 & $65,2 \%$ & $13,0 \%$ & $21,8 \%$ \\
\hline 2003 & $63,6 \%$ & $16,2 \%$ & $20,2 \%$ \\
\hline 2005 & $63,0 \%$ & $18,1 \%$ & $18,9 \%$ \\
\hline
\end{tabular}

Fonte: Inep/MEC (Edudata e Educacenso).

Entretanto, para uma afirmação segura a respeito, é necessária a observação de dados mais atuais os quais não tivemos acesso.

Quanto ao quadro docente, dados da SED/MS de 2003 mostravam que $91,1 \%$ dos professores do ensino médio regular estadual possuíam formação em curso superior, sendo a falta de estabilidade e de habilitação os dois principais problemas a condicionar políticas, dificultar a gestão escolar e repercutir negativamente nos processos e resultados do ensino. Apenas 40,25\% dos professores eram do quadro efetivo, e os não habilitados em exercício chegavam a 42,16\%.

Além de professores temporários e não habilitados, também faltavam condições materiais e pedagógicas básicas em grande parte dos estabelecimentos de ensino que ofereciam ensino médio regular. Entre outros, faltavam: biblioteca, acervos, laboratórios, equipamentos, computadores e acesso à internet (Tabela 7).

Tabela 7 - Condições da oferta do ensino médio regular em estabelecimentos estaduais - Mato Grosso do Sul -1999, 2003 e 2006

\begin{tabular}{|c|c|c|c|c|c|c|c|c|c|c|}
\hline \multirow[t]{2}{*}{ Ano } & \multicolumn{2}{|c|}{$\begin{array}{l}\text { Total de } \\
\text { escolas }\end{array}$} & \multicolumn{2}{|c|}{$\begin{array}{c}\text { Com } \\
\text { biblioteca }\end{array}$} & \multicolumn{2}{|c|}{$\begin{array}{c}\text { Com } \\
\text { laboratório } \\
\text { de } \\
\text { informática }\end{array}$} & \multicolumn{2}{|c|}{$\begin{array}{c}\text { Com } \\
\text { laboratório } \\
\text { de ciências }\end{array}$} & \multicolumn{2}{|c|}{$\begin{array}{c}\text { Com acesso } \\
\text { à internet }\end{array}$} \\
\hline & Número & $\%$ & Número & $\%$ & Número & $\%$ & Número & $\%$ & Número & $\%$ \\
\hline 1999 & 244 & 100 & 148 & 61 & 10 & 4 & 32 & 13 & 25 & 10 \\
\hline 2003 & 265 & 100 & 167 & 63 & 44 & 17 & 34 & 13 & 89 & 34 \\
\hline 2006 & 292 & 100 & 185 & 63 & 157 & 54 & 48 & 16 & 0 & 0 \\
\hline
\end{tabular}

Fonte: Inep/MEC

Observamos que a política de dotação dos estabelecimentos com a infraestrutura indispensável à qualificação do ensino é insatisfatória. A melhoria mais expressiva no período de 1999 a 2006 foi o aumento da taxa de estabelecimentos que passaram a contar com laboratório de informática, mas o acesso à internet continuou não resolvido.

Embora recorrente, a questão das condições apropriadas continua a ser um dos desafios na educação pública estadual sul-mato-grossense, pois a falta de infraestrutura escolar adequada dificulta a promoção da qualidade do ensino médio. Nos anos 1980, Fletcher e Castro (1986), examinando as condições internas das escolas públicas, constataram 
ser essa uma faceta do problema da qualidade do ensino no País. Plank, Sobrinho e Xavier (1990) mostraram que a abordagem do problema da qualidade da educação deveria ser iniciada pelo reconhecimento de que, num grande número de escolas com ensino fundamental do País, faltava o necessário para que se pudesse realizar a tarefa educacional. A situação certamente não era melhor no ensino médio que, geralmente, é ofertado nos mesmos estabelecimentos que o ensino fundamental.

Nos anos 1990, a legislação e o planejamento educacionais remeteram à definição de padrão mínimo de oportunidades educacionais no ensino (Cury, 2002). Embora diretrizes e estratégias da política educacional entre elas as possibilitadas pela Emenda Constitucional $n^{\circ} 14$, pelas Leis $n^{\circ}$ 9.394/96, no 9.424/96 e no 10.011/2000 - tenham propiciado algum avanço quanto a isso, intervenções maciças ainda são requeridas no ensino médio. Mais ainda na perspectiva de manutenção e sustentação da usabilidade, problema que, em geral, não tem sido enfrentado devidamente ao se planejar a dotação material das escolas, principalmente no tocante às novas tecnologias educacionais (Carnoy, 2002).

No Mato Grosso do Sul, assim como em outros Estados brasileiros, a situação do ensino médio deixa patente o imperativo de se assegurar não somente diretrizes relativas a padrão mínimo de qualidade das condições de oferta, mas também a concretização de tal padrão.

Ao lado das questões fundamentais, como a do papel/função e a da democratização do ensino médio, um dos desafios mais urgentes continua a ser o de prover, com qualidade, condições de oferta que sejam condizentes com as necessidades das diversas escolas e com a qualidade desejável nessa etapa da educação básica (Beisiegel, 2002). Isso para fazer face às limitadas condições de alunos e professores para suprirem as suas necessidades básicas de educação e desenvolvimento pessoal e ocupacional/profissional. Muito mais quando pouco eles podem esperar dos equipamentos socioculturais presentes nos municípios, pois estes não se apresentam em melhores condições do que a escola pública. As necessidades e as carências exigem uma provisão suficientemente abrangente, continuada, permanente e adequada às diversas localidades (Freitas, 2003).

O cenário acima descrito permite afirmar que a expansão do ensino médio é um grande desafio para o Estado, e que ela se dê com qualidade, um desafio ainda maior.

\section{Iniciativas estaduais para o ensino médio regular e para a modalidade EJA}

No período de 1999 a 2002, a educação escolar não logrou proeminência no conjunto da atuação governamental estadual. No entanto, a política para o setor pôs acento na mudança do modelo de gestão educacional e enfatizou a inclusão, mediante iniciativas que buscaram conjugar ações do setor social (em sentido estrito) e educacional (Freitas, 2003). 
A proposta "Escola Guaicuru: vivendo uma nova lição" (Mato Grosso do Sul, 1999) anunciou a educação como um direito de todos e um dos pressupostos básicos para a cidadania ativa. Seu objetivo principal seria construir uma escola pública efetiva na democratização do acesso e da gestão, na permanência e na progressão escolar do aluno e na "qualidade social" da educação. A mediação seria o processo "Constituinte Escolar", com o qual se chegou à elaboração do Plano de Educação da Rede Estadual de Ensino de Mato Grosso do Sul (2001-2010), aprovado em 28 de junho de 2001, no $1^{\circ}$ Congresso Estadual da Constituinte Escolar (Mato Grosso do Sul, 2001).

Todavia, com a mudança do secretário de educação em junho de 2001, a proposta não teve prosseguimento, embora não tenha sido formalmente suspensa ou substituída. A nova administração voltou-se para os problemas organizacionais, administrativos e burocráticos da rede escolar estadual.

Quanto ao ensino médio, observou-se que a política da Escola Guaicuru (Mato Grosso do Sul, 2000a, 2000b, 2000c, 2000d, 2000e, 2000f, 2000g) propugnava o seu redimensionamento e fortalecimento, tendo como estratégia a definição de uma proposta político-pedagógica referencial com vistas a um novo currículo, cujos eixos básicos seriam: formação cultural (apropriação de elementos culturais/produção cultural), formação econômica (fundamentos do sistema produtivo e direitos do trabalhador) e formação política (formação para o exercício da cidadania).

A reorganização curricular no ensino médio noturno buscaria fazer frente ao abandono, à reprovação, ao ensino descontextualizado, à jornada de trabalho somada com a de estudo. Para tanto, foi implantado o projeto Aulas Programadas, o qual continha medidas que permitiram à escola:

- flexibilizar o primeiro e o último tempo de aula, substituindo aulas regulares por projetos de pesquisa sobre temas relacionados a conteúdos trabalhados em classe, sob orientação dos professores;

- oferecer aulas diárias de estudos destinadas ao desenvolvimento das disciplinas das três áreas de conhecimento nacionalmente fixadas e, também, aulas diárias para orientação de projetos de pesquisa.

As atividades de "pesquisa" podiam ser desenvolvidas fora da escola, sendo a presença do aluno computada mediante apresentação de registros da execução da atividade. Para cada turma, havia um professor-orientador, que permanecia na escola para sanar dúvidas no desenvolvimento dos projetos.

O ensino médio na modalidade EJA foi regulamentado pelo Conselho Estadual de Educação do Estado de Mato Grosso do Sul por meio da Deliberação CEE/MS n 6.220/2001. De oferta obrigatória e gratuita pelo poder público e facultativa ao setor privado, a EJA destinou-se àqueles que não tiveram acesso à escolarização ou continuidade de estudos na idade própria, por meio de cursos e exames supletivos. 
A matrícula na modalidade EJA foi autorizada para pessoas com 14 anos completos, no ensino fundamental, e 17 anos completos, no ensino médio. A idade mínima para a conclusão do ensino fundamental foi estabelecida em 15 anos, e em 18 anos para o médio. Essa redução de idade para ingresso foi uma das medidas governamentais de estímulo à migração de adolescentes do ensino regular para a EJA, conforme mostrado neste texto. A frequência mínima exigida ao aluno era de $80 \%$ do total da carga horária de cada fase do curso. O aproveitamento de estudos obtido por meios formais ou informais era realizado mediante classificação do aluno em qualquer uma das fases do curso.

O ensino médio EJA, segundo determinação legal, visou instrumentar os educandos para a compreensão da realidade sociopolítica e cultural e ampliar sua capacidade de participação, para a construção de uma nova ordem social. Para isso, deveria oferecer currículo e ensino intencionalmente a serviço dos interesses populares (Mato Grosso do Sul, 2000d), organizando-se de três formas.

A "EJA oportunidade 1" consistia em ensino fundamental organizado em dois anos com quatro fases de 600 horas cada e ensino médio de um ano com duas fases também de 600 horas cada. A carga horária de aula diária fixada era de três horas. O mecanismo de reclassificação permitia progressão frente a evidências de domínio das "competências requeridas" e cumprimento de $80 \%$ da carga horária total de cada uma das fases. As disciplinas Educação Artística, Língua Estrangeira e Ensino Religioso eram cursadas nas classes, com atividades realizadas em forma de oficinas, em horários diferentes do fixado para as aulas dos demais componentes curriculares. Eram também oferecidos estudos orientados, de modo que o aluno completasse carga horária também em outros espaços escolares que não a sala de aula ou a oficina.

A "EJA oportunidade 2" proporcionava uma organização curricular na forma de alternância regular de períodos de estudos para jovens e adultos não alfabetizados da zona rural. Compreendia o Tempo Escola, ou seja, períodos de frequência à escola com carga horária intensiva de aula na época do ano civil em que isso fosse possível, e, também, o Tempo Comunidade, que consistia na continuidade do ensino por meio de atividades programadas pelos professores e desenvolvidas pelos alunos fora da escola.

A "EJA oportunidade 3" propiciava a matrícula por componente curricular para alunos com idade superior a 17 anos, sendo disponibilizada nos 12 meses do ano. As aulas coletivas eram opcionais para o aluno, assim como o atendimento individual ou em pequenos grupos. Cada componente curricular cumprido com aproveitamento era certificado, e a conclusão ocorria somente mediante aprovação em todos os componentes exigidos.

Diversos ajustes foram efetuados no processo de implementação da política acima descrita (Mato Grosso do Sul, 2003a, b, c, d).

Também foi elaborado o Referencial Curricular do Ensino Médio, cuja publicação somente aconteceu em 2004. Com orientação 
teórico-metodológica histórica, o Referencial propunha para as três áreas (Ciências da Natureza, Matemática e suas Tecnologias; Ciências Humanas e suas Tecnologias; Linguagens, Códigos e suas Tecnologias) uma abordagem organizada por três temas: o mundo antigo, a Europa medieval e a modernidade. Tinha em vista a superação do modelo fragmentado, especializado e disciplinar do conhecimento.

Em 2003, a política educacional do Estado passou por novos direcionamentos, destacando-se duas iniciativas associadas: a instituição e a organização do Sistema Estadual de Ensino, pela Lei no 2.787, de 24 de dezembro de 2003 (Mato Grosso do Sul, 2004a), e a elaboração do Plano Estadual de Educação de Mato Grosso do Sul, aprovado pela Lei no 2.792, de 30 de dezembro de 2003 (Mato Grosso do Sul, 2004b).

A primeira lei fixou as prioridades do setor, a saber: erradicação do analfabetismo; melhoria das condições e da qualidade do ensino; universalização do atendimento ao ensino obrigatório e progressiva universalização da educação infantil, do ensino médio e da educação superior; aprimoramento da formação humanística, científica e tecnológica; progressiva ampliação do tempo de permanência do aluno na escola no ensino fundamental; gestão democrática da educação de forma evolutiva e abrangente.

Pretendendo expressar um "pacto social", o Plano Estadual de Educação se propôs a orientar a ação dos órgãos e das instituições da educação escolar no Estado, reafirmando as prioridades apontadas no Plano Nacional de Educação:

[...] garantia de ensino fundamental obrigatório a todas as crianças de 7 a 14 anos, assegurando o seu ingresso e permanência na escola e a conclusão desse ensino; garantia de ensino fundamental a todos os que a ele não tiveram acesso na idade própria ou que não o concluíram; ampliação do atendimento nos demais níveis de ensino; valorização dos profissionais da educação; desenvolvimento de sistemas de informação e de avaliação em todos os níveis e modalidades de ensino, inclusive na educação profissional. (Mato Grosso do Sul, 2004b, p. 14).

Nesse Plano, as diretrizes estabelecidas para o ensino médio foram: ampliação das possibilidades de acesso/oferta com qualidade, mediante medidas que assegurassem os recursos financeiros; investimento na formação inicial e continuada do professor; medidas administrativas e pedagógicas no sentido da correção do fluxo escolar.

Os objetivos e as metas estabelecidos referiram-se a: instalações físicas; padrões mínimos de infraestrutura; expansão da oferta; profissionais capacitados para atender laboratórios de informática e de ciências; capacitação continuada para professores; recursos financeiros específicos para o ensino médio; projetos e programas voltados para erradicação da violência, prevenção ao uso indevido de drogas, à prostituição e à discriminação; ações voltadas para a educação ambiental e para a cidadania; estabelecimento de critérios para as parcerias; adequação do ensino médio às necessidades da população do campo; oferecimento de merenda escolar para o ensino médio; incentivo à permanência por mais 
tempo do aluno na escola; educação de jovens e adultos para a população do campo; criação de mecanismos para a redução dos índices de repetência e evasão escolar; articulação entre as instituições de ensino; transporte escolar rural e urbano para atendimento a alunos e professores, incluindo adaptação àqueles com necessidades educacionais especiais; elaboração de referenciais curriculares para essa etapa de ensino; acompanhamento, pela comunidade escolar, da gestão e da aplicação de recursos financeiros na escola.

A partir do referido Plano, a SED elaborou o projeto político-educacional da gestão 2003-2006, intitulado "Escola inclusiva: espaço de cidadania". Seus três eixos eram: democratização do acesso, da permanência e da progressão escolar; democratização do saber e da qualidade; e democratização da gestão. A "qualidade social" que o referenciava foi assim expressa: "Entender a educação como direito de todos, fazendo da escola um espaço gerador e alimentador da cidadania e da diversidade" (Mato Grosso do Sul, 2003, p. 16).

Embora tenha enviado às escolas o Referencial Curricular do Ensino Médio, cuja elaboração foi antes mencionada, a SED reorganizou o currículo do ensino médio em torno de três eixos: formação científico-cultural, formação político-econômica e formação tecnológica. A metodologia de projetos foi orientada, a partir de 2003, de modo a respeitar a autonomia das escolas, podendo cada uma decidir sobre a inclusão ou não das aulas de projetos.

Quanto à proposta pedagógica das escolas, a SED instituiu, em 2003, uma comissão encarregada de elaborar subsídios voltados para a sua rede escolar. O documento resultante apresentou orientações gerais referentes ao processo, ementas curriculares propostas pela SED para o ensino fundamental e médio e orientações pedagógicas sobre políticas específicas, tais como educação escolar indígena, educação especial e educação do campo (Mato Grosso do Sul, 2003e).

As orientações gerais deixaram claro que cabia ao coletivo escolar definir os fundamentos teóricos de sua proposta pedagógica, sem deixar de observar a legislação vigente. Com isso, formalizou-se o abandono dos fundamentos da política e da gestão da educação básica da Escola Guaicuru.

No período de 2003 a 2006, a gestão do ensino médio, usando aportes financeiros e técnicos do Programa de Melhoria e Expansão no Ensino Médio (Promed) do MEC priorizou a capacitação (de professores, diretores, coordenadores pedagógicos, assessores técnicos), a compra de material didático e equipamentos escolares e a elaboração de diretrizes curriculares.

Em outubro de 2003, a Superintendência de Políticas de Educação apresentou, para discussão, uma proposta de reestruturação curricular para o ensino noturno na rede estadual (Mato Grosso do Sul, 2003c). Evocando os compromissos assumidos pelo Brasil em Jomtien (1990) e Dakar (2000), o documento base trouxe as matrizes curriculares para os ensinos fundamental e médio regulares oferecidos no noturno. 
Essa matriz suprimia a separação entre "base nacional comum" e "parte diversificada", que vigorava no currículo até então. Com isso, a carga horária destinada à parte diversificada foi redistribuída entre as disciplinas das três áreas do conhecimento acima mencionadas. Com implantação prevista para 2004, essa matriz curricular estabeleceu cinco aulas diárias, cinco dias da semana e 200 dias letivos anuais. A duração da aula, de 50 minutos, propiciava 1.000 horas-aula anuais (834 horas).

A nova matriz curricular incluía o que denominou ementa curricular. Basicamente, uma lista de tópicos e subtópicos de conteúdos a serem tratados em cada disciplina.

No ensino médio regular noturno, o período de 1999 a 2006 - gestão do Governo Popular - registrou a manutenção de medidas de "flexibilização" do tempo de aula presencial. O empenho foi em melhor regular práticas escolares que se mostraram contraproducentes, porque levaram a:

- redução, em algumas escolas, do trabalho de professores e alunos com a criação de um dia livre na semana, devido à concentração, num único dia, das cinco horas-aula semanais dedicadas a projetos de pesquisa e ensino;

- não permanência do professor na escola para o atendimento a alunos durante o desenvolvimento dos projetos de pesquisa e ensino;

- descontentamento de professores e dificuldades administrativas no tocante à lotação, surgidas com o deslocamento de carga horária da base nacional comum para a parte diversificada do currículo, na qual seriam operacionalizados os eixos de formação da proposta político-pedagógica "referencial" para a rede estadual, com o uso da metodologia de projetos;

- confusão entre dinâmicas pedagógicas criativas, estimulantes e comprometidas com o projeto político-pedagógico proposto, e atividades que privilegiavam a diversão ou que exigiam condições inexistentes para o conjunto da rede.

Outros problemas, não menos importantes que os mencionados, ainda careciam de providências eficazes (já previstas no Plano Estadual), destacadamente:

- a capacitação docente, com vistas a mudanças nas práticas didático-pedagógicas e no currículo escolar, o planejamento e o trabalho docente de forma integrada e contextualizada;

- o tempo/espaço para que o professor possa estudar;

- a provisão do ensino médio com recursos mínimos indispensáveis (materiais e financeiros) para a viabilização da proposta educacional formulada;

- a prática de avaliação da escola e pela escola;

- a quase inexistência da recuperação dos alunos com aproveitamento insatisfatório. 
Basicamente, é possível afirmar que a política de ensino médio no Estado de MS se ressentiu da falta de continuidade político-administrativa, em consequência da troca de secretários de educação e dos rearranjos nas equipes de trabalho da SED nas gestões de 1999 a 2002 e de 2003 a 2006. O currículo apareceu, em todo momento, como o foco central dessa política.

Cabe mencionar que os mecanismos de democratização da rede estadual de ensino, de 1999 a 2006, não pareceram suficientes para evitar o distanciamento da SED das unidades escolares. Essa foi uma das dificuldades da gestão educacional largamente apontada por diretores escolares, que afirmam estar a escola escassamente acompanhada e assistida, especialmente nas questões de cunho pedagógico (Freitas, 2003).

Quanto ao ensino médio na modalidade EJA, a Deliberação CEE/MS $n^{\circ}$ 6.220/2001 continuou a viger, estimulando a migração do ensino médio regular para essa modalidade.

No período posterior a 2006, o foco da política educacional para a escolarização média estadual passou a ser a integração do ensino médio com a educação profissional técnica de nível médio. A SED empenhou-se em credenciar unidades escolares, aprovar projetos e autorizar o funcionamento de cursos técnicos integrados ao ensino médio, destacadamente o Curso Técnico em Informática.

Com o lançamento do Programa Ensino Médio Inovador do MEC, em abril de 2009, o Estado tem como desafio reorganizar o currículo do ensino médio. Esse Programa propõe o estabelecimento de uma nova organização curricular com articulação interdisciplinar voltada para o desenvolvimento de conhecimentos, saberes, competências, valores e práticas. Para tanto, estabelece um referencial de proposições curriculares e condições básicas que devem orientar os projetos escolares, buscando inter-relações entre os eixos trabalho, ciência, tecnologia e cultura. O Programa é proposto no contexto do Decreto n . 6.094/2007 e do Plano de Desenvolvimento da Educação (PDE).

Em dezembro de 2009, por meio da Resolução n 2.318/2009, a SED resolve organizar o currículo e o regime escolar do ensino fundamental e do médio nas escolas estaduais, com base em deliberações do CEE de 2006 e 2007. Determina que o currículo do ensino médio, organizado em anos e com a duração de três anos, contenha obrigatoriamente uma base nacional comum e uma parte diversificada, ambas organicamente integradas, contribuindo para a promoção do cidadão, por meio da educação articulada com o mundo do trabalho, a prática social, a preparação para o exercício da cidadania e a preparação básica para o trabalho.

A estruturação do currículo deveria dar-se em três áreas de conhecimento:

a) Linguagens, Códigos e suas Tecnologias, contemplando as disciplinas de Língua Portuguesa, Literatura, Artes e Educação Física;

b) Ciências da Natureza, Matemática e suas Tecnologias, que abrange as disciplinas de Física, Química, Biologia e Matemática;

c) Ciências Humanas e suas Tecnologias, que abarca as disciplinas de História, Geografia, Sociologia e Filosofia. 
A parte diversificada contempla as disciplinas de Redação e Línguas Estrangeiras Modernas, cabendo à comunidade escolar fixar qual é de frequência obrigatória e qual é facultativa.

A resolução acima citada faculta ao ensino noturno (fundamental e médio) a flexibilização de dez minutos no primeiro e no quinto tempo, por meio de estudos orientados "com efetiva participação do aluno, para atendimento às suas necessidades específicas".

O ensino médio na modalidade EJA vem sofrendo modificações com a revogação da Deliberação CEE/MS no 6.220/2001, substituída pela Deliberação CEE/MS nº 909/2009, a qual estabeleceu normas para cursos de EJA e exames supletivos no sistema estadual de ensino de Mato Grosso do Sul. As alterações foram basicamente estas:

- deixar a organização da oferta do curso a critério das escolas;

- admitir a organização por alternância regular de períodos de estudos somente para as escolas localizadas no campo;

- fixar em 18 anos a idade mínima para ingresso na EJA tanto no ensino fundamental como no médio, na forma presencial ou a distância;

- estabelecer frequência mínima de 75\% da carga horária total das horas letivas para aprovação em cada módulo, segmento, período, ciclo ou outras formas de organização;

- proibir as escolas de usar na EJA procedimentos de aceleração de estudos, avanço escolar e progressão parcial.

Por meio da Resolução SED n².317/2009, foi aprovado o Projeto Pedagógico dos Cursos de Educação de Jovens e Adultos, nas etapas do ensino fundamental e do médio - EJA-I-MS, da SED/MS -, a ser operacionalizado pelas escolas da rede estadual de ensino, pelo prazo de cinco anos. Não tivemos acesso a esse documento. De todo modo, temos aí uma iniciativa animada por uma lógica de regulação centralizada.

Chamamos a atenção para o fato de que a modalidade regular de escolarização básica conta com ferramentas e processos avaliativos e de monitoramento de metas quanti-qualitativas projetadas. Entretanto, a modalidade EJA tem ficado praticamente entregue às formas de compreender e praticar a flexibilidade do atendimento a adolescentes, jovens e adultos, cuja trajetória de escolarização tardia é enfrentada com uma pedagogia aligeirada que sequer consegue ser compensatória e eficazmente focalizada. Exames de certificação e o Exame Nacional do Ensino Médio (Enem) não são concebidos para avaliar a expansão do ensino médio e a qualidade que ela concretiza.

\section{Finalizando}

Podemos dizer que a expansão do ensino médio com qualidade é ainda um grande desafio para o Estado de MS, sendo que as vias próprias para tanto não nos parecem ser a modalidade EJA nem a articulação desse 
ensino com a formação técnica profissional. Sem dúvida, estas são as que requerem menor esforço na esfera do financiamento e que, talvez, possam responder mais prontamente a demandas de setores da sociedade motivadas por óticas conservadoras, preocupação com a sobrevivência, desconhecimento de alternativas e outras tantas.

Porém, no nosso entendimento, as vias tomadas pelo Estado não são as que melhor podem contribuir para mudar o perfil educacional da sua população adolescente e jovem, de modo a lhes assegurar elementos de formação escolar básica que são indispensáveis aos requerimentos individuais e sociais emergentes no mundo atual. Essa formação precisa ser combinada com outras iniciativas de enriquecimento de experiências culturais - tarefa que necessita mobilizar a sociedade e o Estado.

A expansão do ensino médio pode ser mais profícua por meio de uma via na qual sejam conjugadas duas estratégias:

a) equacionamento da falta de condições propícias tanto no equipamento escolar como nos equipamentos culturais, em cada localidade;

b) integração da educação escolar com mediações formativas na esfera social e cultural, efetivamente comprometida com a proteção integral do adolescente.

É preciso levar na devida conta que as condições de vida de alunos e seus professores, em muitos municípios do Estado, não lhes permitem autoqualificar as suas experiências socioculturais e educacionais, o que evidenciou a pesquisa sobre o ensino médio noturno (Freitas, 2003; Oliveira, Sousa, 2008).

Entre as condições necessárias, estão as infraestruturais, como bibliotecas (com acervo adequado e atualizado), laboratórios para as várias áreas (devidamente instalados, com manutenção, condições operacionais e atualização asseguradas) e docentes estáveis e com condições (tempo e meios) de estudos de reciclagem e aperfeiçoamento. Está o imperativo de fomento do ensino, mediante bolsa de estudo que possibilite e exija dos adolescentes a dedicação exclusiva ao seu processo de escolarização e desenvolvimento sociocultural. A sociedade tem mais a ganhar com um adolescente ocupado com seu desenvolvimento e sua inserção social do que prestando serviço pouco (ou nada) qualificado e mal remunerado.

Um caminho a ser construído é o de conjugação dos esforços da escola com os equipamentos socioculturais locais. Porém, a estratégia para tanto requer ir-se além de colaborações e articulações eventuais, gestando e sustentando um "plano único" de formação e desenvolvimento integrais de adolescentes e jovens. Isso exige que o poder público se empenhe no combate ao insulamento setorial na prestação do legítimo atendimento às necessidades educacionais e culturais da população. Para começar, promovendo a interlocução e a ação consociada dos organismos e atores governamentais no espaço local como parte da constituição de uma esfera pública. 
Não nos parece ser possível avançar sem investimentos bem planejados, cuja execução se efetive e seja monitorada em conjunto, com resultados avaliados interna e externamente.

A pesquisa mostrou-nos que não bastam propostas concebidas com participação dos diretamente envolvidos, de organizações sociais, de pesquisadores e outros. Nem os esforços de reformulá-las frequentemente.

O primeiro desafio sul-mato-grossense está em vencer a persistente dissociação entre concepção de propostas e criação de condições de sua viabilidade (avaliação, planejamento e financiamento conjugados e congruentes), assim como de sua continuidade e seu aprimoramento.

Enfrentar o desafio de escolher vias producentes é uma urgência, pois a qualidade da expansão do ensino médio não só impacta a democratização da educação superior, a qualidade desta, mas também todas as relações sociais nas quais formação e desenvolvimento das pessoas são essenciais. Por isso, a lógica conservadora que insiste em restringir a responsabilidade e a ação públicas (Estado e sociedade) precisa ser superada, efetivando na prática a educação como uma das questões sociais fundamentais.

\section{Referências bibliográficas}

BEISIEGEL, C. de R. O ensino médio sob a perspectiva da educação básica. In: ZIBAS, D.; AGUIAR, M.; BUENO, M. (Orgs.). O ensino médio e a reforma da educação básica. Brasília: Plano, 2002. p. 33-45.

BRASIL. Ministério da Educação. Ensino médio inovador. Brasília: abril 2009. Disponível em: <www.mec.gov.br>. Acesso em: 6 fev. 2010.

CARNOY, M. Mundialização e reforma da educação: o que os planejadores devem saber. 2. ed. Brasília: Unesco Brasil, 2002.

CURY, C. R. J. Políticas atuais para o ensino médio e a educação profissional de nível técnico: problemas e perspectivas. In: ZIBAS, D.; AGUIAR, M.; BUENO, M. (Orgs.). O ensino médio e a reforma da educação básica. Brasília: Plano, 2002. p. 15-32.

FLETCHER, Philip. R.; CASTRO, Cláudio de M. A escola que os brasileiros frequentaram em 1985. Rio de Janeiro: Ipea, Iplan, 1986.

FREITAS, D. N. T. de. Ensino médio noturno: registro e análise de experiências - Estado de Mato Grosso do Sul. Dourados, MS, 2003. (Não publicado).

MATO GROSSO DO SUL (Estado). Proposta de educação do Governo de Mato Grosso do Sul: 1999/2002. Campo Grande: SED/MS, 1999. (Cadernos da Escola Guaicuru 1). 
MATO GROSSO DO SUL (Estado). O ensino médio na Escola Guaicuru: proposta político-pedagógica para Mato Grosso do Sul. Campo Grande: SED/MS, 2000a. (Cadernos da Escola Guaicuru 2).

Política educacional. Campo Grande: SED/MS, 2000b. (Série Constituinte Escolar: construindo a escola cidadã).

. Ensino noturno. Campo Grande: SED/MS, 2000c. (Série Constituinte Escolar, $3^{\circ}$ momento - Caderno Temático, n. 9).

Educação de Jovens e Adultos e Educação Profissional. Campo Grande: SED/MS, 2000d. (Série Constituinte Escolar, $3^{\circ}$ momento Caderno Temático 1).

Assessoria técnica escolar. Campo Grande: SED/MS, 2000e. (Série Constituinte Escolar, $3^{\circ}$ momento - Caderno Temático 4).

. Resolução SED no 1.451, de 18 de dezembro de 2000. Dispõe sobre organização curricular dos anos finais do Ensino Fundamental, sobre o Regime Escolar do Ensino Fundamental e do Ensino Médio das unidades escolares da Rede Estadual de Ensino, e dá outras providências. Diário Oficial do Estado, n. 5412, p. 7-10, 21 dez. 2000f.

Resolução SED n 1.453, de 18 de dezembro de 2000.

Estabelece as normas para as unidades escolares da Rede Estadual de Ensino quanto ao Plano Curricular Unificado do Ensino Médio, e dá outras providências. Diário Oficial do Estado, n. 5412, p. 13-14, 21 dez. $2000 \mathrm{~g}$.

Deliberação CEE/MS nº 6.220, de 1º de junho de 2001.

Fixa normas para cursos de Educação de Jovens e Adultos

e Exames Supletivos e revoga as Deliberações CEE/MS n ${ }^{\text {os }} 5.306 / 1998$,

$5.726 / 2000$ e 5.836/2000 e dá outras providências. Revogada pela Deliberação CEE/MS no 9.090/2009. Diário Oficial do Estado, Campo Grande, 13 jun. 2001. Disponível em:

<http://www.cee.ms.gov.br/templates/apresentacao/componentefixo/ gerador/gerador.php?pag $=1593 G$ template $=19>$. Acesso em: 6 fev. 2010 .

. Plano de Educação da Rede Estadual de Ensino de Mato Grosso do Sul. Campo Grande: SED/MS, 2001.

. Perspectivas pedagógicas para o ensino médio: proposta político-pedagógica, Governo Popular de Mato Grosso do Sul - 19992002. 2. ed. rev. Campo Grande: SED/MS.2002. (Série Fundamentos Político-Pedagógicos). 
MATO GROSSO DO SUL (Estado). Resolução SED no 1.629 , de $1^{\circ}$ de abril de 2003. Estabelece as normas para as unidades escolares da Rede Estadual de Ensino quanto ao Plano Curricular Unificado do Ensino Médio, e dá outras providências. Diário Oficial do Estado, Campo Grande, n. 5970, 2 abr. 2003a.

. Instrução Coebep/SUP/SED no 01/2003, de 30 de abril de 2003. Estabelece orientações sobre Ensino Médio, e dá outras providências. Diário Oficial do Estado de Mato Grosso do Sul, n. 5994, p. 5-7, 12 maio 2003b.

. Ensino noturno. Campo Grande: SED/MS, 2003c. [Não publicado].

Projeto do Curso de Educação de Jovens e Adultos. Campo

Grande: SED/MS, 2003d. [Não publicado].

. Documento orientativo para elaboração ou adequação da proposta pedagógica. Campo Grande: Secretaria de Estado de Educação, 2003e. Disponível em: <www.educar.ms.gov.br> . Acesso em: 14 fev. 2004.

. Escola inclusiva: espaço de cidadania. Campo Grande, SED, 2003f. Disponível em: < http://www.sgi.ms.gov.br/pantaneiro/sites/sed/ geradorhtml/paginasgeradas/ead_3958/pdfs/escola_inclusiva.pdf> . Acesso em: 6 fev. 2010.

Lei $n^{\circ}$. 2.787, de 24 de dezembro de 2003. Dispõe sobre o Sistema Estadual de Ensino de Mato Grosso do Sul e dá outras providências. Campo Grande: SED/MS, 2004a.

. Lei no 2.791, de 30 de dezembro de 2003. Aprova o Plano Estadual de Educação de Mato Grosso do Sul e dá outras providências [publicada no Diário Oficial n 6.153, de 29 de dezembro de 2003]. Campo Grande: SED/MS, 2004b.

. Deliberação CEE/MS no 9.090, de 15 de maio de 2009.

Estabelece normas para Cursos de Educação de Jovens e Adultos e Exames Supletivos no Sistema Estadual de Ensino de Mato Grosso do Sul. Diário Oficial do Estado, Campo Grande, n. 7480, 17 jun. 2009. Disponível em: <http://www.cee.ms.gov.br/templates/apresentacao/ componentefixo/gerador/gerador.php?pag=1593Gtemplate $=19>$. Acesso em: 6 fev. 2010.

. Resolução/SED n 2.318, de 29 de dezembro de 2009.

Dispõe sobre a organização curricular e o regime escolar do ensino fundamental e do ensino médio, nas unidades escolares da Rede 
Estadual de Ensino, e dá outras providências. Diário Oficial do Estado, Campo Grande, n. 7.614, p. 7-13, 4 jan. 2010. Disponível em:

$<$ http://aacpdappls.net.ms.gov.br/appls/legislacao/sed/legased.nsf/vwre solucao?OpenViewGStart $=1 \mathrm{GCount}=30 \mathrm{GExpand}=2 \# 2>$. Acesso em: 6 fev. 2010.

MATO GROSSO DO SUL (Estado). Resolução SED n 2.317/2009. Aprova o Projeto Pedagógico dos Cursos de Educação de Jovens e Adultos, nas etapas do Ensino Fundamental e do Ensino Médio - EJA-I-MS, da Secretaria de Estado de Educação/MS, e dá outras providências. Diário Oficial do Estado, Campo Grande, n. 7614, p. 7, 4 jan. 2010. Disponível em: <http://aacpdappls.net.ms.gov.br/appls/legislacao/sed/legased.nsf/v wresolucao?OpenView GStart $=16$ Count $=306$ Expand $=2 \# 2>$. Acesso em: 6 fev. 2010.

OLIVEIRA, R. P. Da universalização do ensino fundamental ao desafio da qualidade: uma análise histórica. Educação G Sociedade, v. 28, n. 100 [nº especial], p. 661-690, out. 2007.

OLIVEIRA, R. P.; SOUSA, S. Z. S. Ensino médio noturno: democratização e diversidade. Educar em Revista, Curitiba, n. 31, p. 53-72, jan./jun. 2008.

PLANK, David N.; SOBRINHO, José Amaral; XAVIER, Antônio Carlos da R. Uma estratégia para a qualidade do ensino fundamental: os padrões mínimos de oportunidades educacionais. Estudos em Avaliação Educacional, São Paulo, n. 2, p. 33-40, jul./dez. 1990.

SCHWARTZMAN, Simon. Os desafios da educação no Brasil. In: SCHWARTZMAN, Simon; BROCK, Colin (Orgs.). Os desafios da educação no Brasil. Rio de Janeiro: Nova Fronteira, 2005. p. 9-51.

Dirce Nei Teixeira de Freitas, doutora em Educação pela Universidade de São Paulo (USP), é professora no Programa de Pós-Graduação em Educação da Universidade Federal da Grande Dourados (UFGD) . Coordena o grupo de estudos e pesquisa "Estado, Política e Gestão da Educação (GEPGE)".

dircenei@terra.com.br

Recebido em 3 de dezembro de 2009.

Aprovado em 19 de abril de 2010. 